\title{
CORRECTION
}

View Article Online

View Journal I View Issue

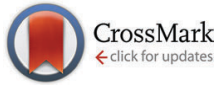

Cite this: J. Mater. Chem. C, 2017, 5,1552

DOI: $10.1039 / \mathrm{c} 7 \mathrm{tc} 90017 \mathrm{a}$

rsc.li/materials-c

\section{Correction: Vacuum-process-based dry transfer of active layer with solvent additive for efficient organic photovoltaic devices}

\author{
Jong Hwa Lee, ${ }^{a}$ Kang Min Kim, ${ }^{a}$ Woongsik Jang, ${ }^{\mathrm{b}}$ Sunyong Ahn, ${ }^{\mathrm{b}}$ Young Yun Kim, ${ }^{\mathrm{a}}$ \\ O. Ok Park ${ }^{\star a}$ and Dong Hwan Wang*b
}

Correction for 'Vacuum-process-based dry transfer of active layer with solvent additive for efficient organic photovoltaic devices' by Jong Hwa Lee et al., J. Mater. Chem. C, 2017, DOI: 10.1039/c6tc04743b.

A sentence is missing from the acknowledgements section of this paper. The full text is provided below with the missing sentence in bold.

The Royal Society of Chemistry apologises for these errors and any consequent inconvenience to authors and readers.

\section{Acknowledgements}

This research was supported by the Basic Science Research Program through the National Research Foundation of Korea (NRF), funded by the Ministry of Science, ICT \& Future Planning (2014R1A1A1002419). This research was also supported by the Climate Change Research Hub of KAIST (grant no. N11160015). The authors appreciate Sung Cik Mun for the assistance with synthesis of HEMA-PUA. This research was supported by the Chung-Ang University Graduate Research Scholarship in 2015.

\footnotetext{
${ }^{a}$ Department of Chemical and Biomolecular Engineering (BK21+ graduate Program), Korea Advanced Institute of Science and Technology, 291 Daehak-ro, Yuseong-gu, Daejeon 305-701, Republic of Korea. E-mail: oopark@kaist.ac.kr

${ }^{b}$ School of Integrative Engineering, Chung-Ang University, 84 Heukseok-ro, Dongjak-gu, Seoul 156-756, Republic of Korea. E-mail: king0401@cau.ac.kr
} 